\title{
SITUAÇÕES DE DESCONFORTO VIVENCIADAS PELO IDOSO HOSPITALIZADO COMA INVASÃO DO ESPAÇO PESSOAL E TERRITORIAL
}

\author{
Uncomfortable Situation Experienced by the Elderly Hospitalized \\ with the Personal and Territorial Invasion \\ Situaciones de Incomodidad Vividas por el Anciano Hospitalizado \\ con la Invasión del Espacio Personal y Territorial
}

Teresa Cristina Prochet ${ }^{1}$

Maria Julia Paes da Silva²

\begin{abstract}
Resumo
A comunicação é a essência da vida e inerente ao ser humano, pois ela traz a possibilidade de as pessoas se relacionarem, compartilhando suas idéias, pensamentos, vivências e sentimentos. Por meio dela somos capazes de nos relacionarmos e assim construirmos uma condição de atendimento e interação com o outro. Esse estudo teve como objetivo identificar as situações de desconforto vivenciadas pelo idoso hospitalizado com a invasão do espaço territorial e pessoal. Pesquisa realizada com 30 idosos hospitalizados em hospital público do interior de São Paulo. Verificou-se que as situações de invasão territorial de desagrado dos idosos foram aquelas relacionadas ao barulho provocado pela equipe e à negligência da preservação da privacidade e das limitações do espaço do idoso. Já as de invasão pessoal estão ligadas à manipulação da unidade do cliente sem seu consentimento e ao desrespeito à intimidade com a banalização da exposição do corpo.
\end{abstract}

Palavras-chave: Idoso. Comunicação Não-verbal. Hospitalização.

\begin{abstract}
Communication is essential for life and inherent to man. Communication brings opportunity for individuals to relate to each other, share ideas, thoughts, life experiences and feelings. It also enables us to exchange information and build an environment to better serve and interact with each other. This paper was aimed to identify personal uncomfortable experience among elderly inpatients regarding privacy and territorial invasion in a public hospital in Sao Paulo, Brazil. 30 elderly patients were interviewed with a standard questionnaire. The most common complaints among hospitalized elder patients were hospital ward noise level; negligence on maintaining privacy and invasion of personal space. Regarding invasion of personal space, many patients complained about being manipulated without previous consent and perceived being treated with disrespect during physical exam with banalization of the human body.
\end{abstract}

Keywords:

Aged. Nonverbal Comunication. Hospitalization.

\section{Resumen}

La comunicación es la esencia de la vida y es inherente al ser humano, pues trajo la posibilidad a la persona de se relacionaren, compartiendo sus ideas, pensamientos, experiencias y sentimientos. A través de la comunicación somos capaces de establecer relaciones con las personas y, así construir condiciones adecuadas de atención y interacción con los demás. El objetivo de este estudio fue identificar las situaciones de incomodidad experimentados por el anciano hospitalizado ante la invasión del espacio territorial y personal. Investigación realizada con 30 ancianos hospitalizados en un hospital público de una ciudad del interior de São Paulo. Se encontró que, a los ancianos les desgustan las invasiones territoriales relacionadas con el ruido causado por el equipo profesional y por la negligencia con la preservación de la intimidad y de las limitaciones del espacio del anciano. Las incomodidades con la invasión personal están relacionados no sólo con el manejo de la cama del cliente sin su consentimiento sino también a la falta de respecto hacia su intimidad y a la sensación de trivialidad con que es tratada la exposición del cuerpo.

Palabras clave:

Anciano. Comunicación no verbal. Hospitalización.

${ }^{1}$ Grupo de Estudo e Pesquisa sobre Comunicação em Enfermagem do CNPq. - Universidade de São Paulo - Escola de Enfermagem - São Paulo. ${ }^{2}$ Grupo de Estudo e Pesquisa sobre Comunicação em Enfermagem do CNPq. - Universidade de São Paulo - Escola de Enfermagem - São Paulo. 


\section{INTRODUÇÃO}

Os avanços da ciência e a melhoria das condições sanitárias constituem as principais razões para a transiçãa demográfica e epidemiológica, que revela como conseqüência $o$ aumento absoluto e relativo da população idosa brasileira. Nos países em desenvolvimento, como é o caso do Brasil, essa transição tem ocorrido de forma acelerada, o que vem tornar necessários a organização dos serviços de saúde e, principalmente, o conhecimento dos profissionais de saúde para se tornarem hábeis em lidar com essa clientela ${ }^{1,2}$.

Para podermos lidar com outro, precisamos utilizar os recursos da comunicação, uma vez que é por meio dela que somos capazes de nos relacionarmos e construirmos uma condição de atendimento e interação com o outro, seja ele idoso ou colega de trabalho.

A comunicação é a essência da vida e inerente ao ser humano, pois traz a possibilidade de as pessoas se relacionarem, compartilhando suas idéias, pensamentos, vivências e sentimentos. Ao se relacionarem, sofrem influências de si próprias, do outro e do ambiente, com isso podendo sentir-se mobilizadas a transformar a realidade na qual estão inseridas ${ }^{3}$.

Comunicar é partilhar. Mas, o que temos partilhado? Umas vezes partilhamos nossas conquistas, as belezas e sentimentos de felicidade; outras vezes, nossas angústias, medos e preocupações. 0 fato é que a comunicação é o processo pelo qual podemos compreender o mundo, nos relacionarmos com os outros e transformarmos a nós mesmos e a realidade 3 .

Comunicação na Enfermagem pode ser entendida como um processo pelo qual a equipe de enfermagem oferece e recebe informações do indivíduo/cliente e sua família, para planejar, executar, avaliar e participar, juntamente com outros membros de outras equipes da assistência, necessárias para a reversão/melhoria/estabilização de suas condições de vida e saúde, incluindo as doenças ou mesmo manutenção/proteção/ promoção de sua saúde.

Silva ${ }^{3}$ ressalta que a comunicação é denominador de todas as ações de Enfermagem e está presente em suas teorias, de maneira mais ou menos explíitita. Refere que comunicação adequada é aquela que tenta diminuir conflitos, mal-entendidos, e atingir objetivos definidos para a solução dos problemas detectados na interação com as pessoas sob seus cuidados ou liderança.

Quando estabelecemos uma comunicação efetiva/afetiva conseguimos compreender o pensar, o agir, o sentir, o desejar, 0 escolher do cliente. Passamos a entendê-lo, como um todo, valorizamos suas experiências e permitimos que ele continue a construir sua história de vida. Quando a Enfermagem compreende essa dimensão, consegue harmonizar o cuidado instrumental e comportamental, tornando o contexto algo significativo e valorizando o momento do cuidar em enfermagem ${ }^{3}$.

A comunicação interpessoal pode ser classificada em: verbal, referindo-se às palavras ditas ou escritas; e não-verbal, aquelas associadas aos gestos, silêncios, expressões faciais, entonação e timbre da voz, toque, aparência física, condições ambientais, posturas corporais, posição e distância interpessoal mantida entre as pessoas ${ }^{3}$.
A comunicação não-verbal nos auxilia para que os sentimentos, os pensamentos, as indagações sejam expressos e, além disso, revela a coerência entre a intenção do comunicador e seu discurso. Pode-se citar que os objetivos da comunicação não-verbal são: complementar o verbal, contradizê-lo, substituílo e/ou, ainda, demonstrar e reconhecer os sentimentos ${ }^{3,4}$.

É sabido que o uso do espaço é uma das dimensões da comunicação não-verbal que influencia o relacionamento interpessoal. A proxêmica estuda o significado social do espaço, ou seja, estuda como o homem estrutura consciente ou inconscientemente o próprio espaço $0^{3,5}$.

Segundo Hall ${ }^{6}$, a utilização do espaço é determinada culturalmente e a percepção da distância e a proximidade são resultados dos sistemas sensoriais (visual, auditivo, olfativo, tato). Em diferentes culturas os canais sensoriais adquirem mais importância do que outros.

A proxêmica estuda o espaço em três aspectos: o espaço de características fixas (p. ex., paredes); o espaço de características semifixas (p.ex., disposição dos mobiliários, obstáculos e adornos); o espaço informal (o território pessoal ao redor do corpo do indivíduo) ${ }^{6}$.

$\mathrm{Na}$ cultura norte-americana, Hall ${ }^{6}$ identificou quatro distâncias interpessoais: distância íntima $(0$ a $50 \mathrm{~cm})$, onde ocorre o contacto físico, o calor humano e a transmissão dos odores; distância pessoal (50 cm a 1,20 m), onde ocorre a maior parte das relações de contato; distância social (1,20 m a 3,60 m), onde não ocorre contacto físico, porém existe 0 contacto visual com o interlocutor; e a distância pública (acima de 3,60 m), onde o contacto visual não é individual, e sim coletivo. A análise proxêmica envolve oito fatores que compõem as suas categorias primárias:


posição básica dos interlocutores (em pé, sentado, deitado).

- Eixo sociofugo-sociopeto $=0$ eixo sociofugo demonstra o desencorajamento da interação, enquanto o sociopeto implica o inverso. Essa dimensão analisa o ângulo dos ombros em relação à outra pessoa; a posição dos interlocutores (face-a-face, de costas um para o outro ou qualquer outra angulação).

- Cinestésico $=$ analisa o posicionamento das partes do corpo em relação ao outro e suas possibilidades de contato.

- Comportamento de contato = este fator analisa as formas de relações táteis como acariciar, agarrar, apalpar, segurar demoradamente, apertar, tocar localizado, roçar acidental ou nenhum contato físico.

- Código visual = verifica o modo de contato visual que ocorre nas interações, como o olho-no-olho ou ausência de contato.

- Código térmico $=$ implica no calor percebido pelos interlocutores.

- Código olfativo = analisa as características e o grau de odores percebidos pelos interlocutores.

- Volume de voz = analisa a percepção dos interlocutores com relação à adequação do tom de voz utilizado pelos envolvidos. 
Esses espaços demarcam áreas de diferentes significados sociais, e o homem considerado saudável desempenha distintos papéis em determinados locais. Já, quando se encontra inserido no contexto hospitalar, sai de seu domicílio, que constitui seu ambiente de domínio, e é admitido num local onde seu espaço territorial precisa ser dividido com pessoas estranhas, num momento especial, quando sua saúde se encontra em crise. Nessa situação em que se encontra fragilizado, pode ser alvo de invasão do seu território e do espaço pessoal, o que, segundo Allekian ${ }^{7}$, o leva a expressar reações como ansiedade, inquietação, luta ou fuga. Na maioria das vezes essas reações dependem da percepção que o indivíduo tem de si mesmo, do outro, dos objetos e das situações que o circundam.

Espaço pessoal representa o quanto nosso corpo suporta a proximidade de alguém; essa resposta, que podemos chamar de tamanho espacial, é individual e varia de um indivíduo para o outro, sendo influenciada pelo tipo de relação que está sendo estabelecida ou mantida com o outro. Já o espaço territorial é a área na qual o indivíduo reivindica como sua, defendendo-a de outras pessoas. Trata-se de uma área não fixa e que é delimitada em função da segurança, privacidade, autonomia e identidade ${ }^{3,6}$.

Estudos revelam que a invasão do espaço territorial e pessoal dos clientes internados não é uma suposição, é uma realidade que precisa ser mais estudada e enfrentada por todos os profissionais envolvidos nesse contexto $5,8,9,10$.

Como a Enfermagem é gente que cuida de gente ${ }^{11}$, e no exercício de suas atividades estabelece relações humanas com o cliente e equipe multidisciplinar, investigar quais comportamentos da equipe de saúde são reconhecidos pelos idosos quando eles são invadidos em seu espaço pessoal e territorial, durante sua hospitalização, representa uma contribuição na busca da qualidade da assistência na saúde, tão desejada e esperada pelos profissionais que têm a intenção de assumir a responsabilidade sob si próprio e pelo papel que exercem sob o outro.

\section{OBJ ETIVO}

- Identificar as situações de desconforto vivenciadas pelo idoso hospitalizado com a invasão do espaço territorial e pessoal.

\section{MÉTODO}

\section{Tipo, Campo, Sujeito do Estudo}

Estudo do tipo exploratório, descritivo, transversal e de campo, desenvolvido em um hospital geral público do interior paulista. A pesquisa foi realizada no período de junho a agosto de 2007 com os idosos internados nas unidades de clínica médica e/ou cirúrgica, seguindo os seguintes critérios de inclusão:

- Cliente com idade igual ou superior a 60 anos, internado por, no mínimo, 48 horas, período em que já tinha tido contacto com o ambiente e sido submetido ao atendimento da equipe de saúde.

- Cliente que, após informação dos objetivos e da metodologia do trabalho, aceitou participar espontaneamente da pesquisa, firmando a autorização por meio de assinatura do Termo de Consentimento Livre e Esclarecido.
- Cliente que foi capaz de responder adequadamente à escala conhecida como Mini-Exame do Estado Mental de Folstein ${ }^{12}$.

\section{Coleta de Dados}

Após aprovação do projeto pelo Comitê de Ética em Pesquisa com Seres Humanos do Hospital Regional de Assis ( $n^{\circ}$ 59/ 2007), este estudo foi realizado mediante a aplicação de um questionário para caracterização do idoso e da Escala de Medida do Sentimento diante da Invasão do Espaço Territorial e Pessoal - EMS-FIETEP, validado por Sawada ${ }^{5}$. Posteriormente, perguntou-se ao idoso se ele podia contar algum incidente ocorrido durante a sua hospitalização que estivesse relacionado à invasão pessoal ou territorial, e como ele se sentiu perante tal acontecimento. É importante registrar que, pelo fato de ter respondido à Escala, sabia o conceito de invasão de espaço pessoal e territorial A resposta do idoso foi gravada como forma de garantir fidedignidade nas anotações.

\section{RESULTADOS E ANÁLISE DE DADOS}

\section{Sobre as características dos idosos pesquisados}

Durante o período de coleta de dados, obtiveram-se 30 idosos que se enquadraram nos critérios de seleção, sendo $66,7 \%$ do sexo masculino e $33,3 \%$ do feminino; divididos entre clientes clínicos (40\%) e pré-cirúrgicos (60\%); faixa etária entre 60 e 82 anos, sendo a média de 68 anos. A religião católica foi professada por $83,3 \%$ dos entrevistados, seguida pela evangélica com $10 \%$ e nenhuma por $6,7 \%$. A média da escala de Folstein aplicada antes da entrevista foi de 24,2 pontos (18 e 28 são os limites inferior e superior). Quanto ao número de anos de estudo, 86,7\% possuíam até 4 anos, 10,0\%, 5 anos, e apenas 3,3\% possuíam 12 anos ou mais de estudo. Em relação ao estado civil, $60 \%$ eram casados, $23,3 \%$ viúvos, $10 \%$ divorciados e somente $6,7 \%$ solteiros. Quanto ao número e tipo de pessoas que residem com os idosos pesquisados, os dados revelaram que somente $16,7 \%$ residiam sozinhos, a maioria morava com seus cônjuges. Aplicando a escala de determinação de dependência proposta por Waldow ${ }^{13}, 0$ resultado foi que a maioria era independente (90\%), 6,7\% eram dependentes de grau II e 3,3\%, de grau I.

\section{Sobre a invasão pessoal e territorial}

Analisando os dados obtidos com a aplicação da Escala de Medida do Sentimento diante da Invasão do Espaço Pessoal e Territorial, pudemos verificar que a maioria dos pacientes se importou mais com a invasão territorial do que com a invasão pessoal. Isso vai ao encontro dos estudos de Allekian ${ }^{7}$ e de Sawada ${ }^{5}$, nos quais obtiveram os mesmos resultados, e uma das justificativas possíveis é dada pelo fato de o indivíduo hospitalizado já possuir consciência antecipada da necessidade de aproximação física requerida nos momentos de cuidados pela equipe de saúde; isso faria com que ele tivesse um grau maior de aceite (tolerância) da invasão do espaço pessoal, mesmo sendo independente no seu cuidar ${ }^{13}$, conforme já relatado.

As situações de invasão territorial consideradas mais desagradáveis indicadas pelos idosos referem-se ao desrespeito e à mudança do espaço físico, expressa quando sem a permissão 
do idoso; quando o pessoal de enfermagem mexe na gaveta onde estão guardados seus pertences pessoais $(73,4 \%)$ e quando a mesa de cabeceira é mudada de lugar numa posição que ele não consegue alcançar (56,7\%). Além disso, foi também mencionado pelos idosos o quanto é desagradável, enquanto estão dormindo, o pessoal de enfermagem acender a luz do quarto para prestar cuidados ao cliente que está ao lado, interrompendo seu descanso e sono ${ }^{14}$.

As duas situações de invasão pessoal consideradas mais desagradáveis apontadas pelos idosos são aquelas quando "o pessoal de enfermagem realiza um procedimento técnico numa região mais íntima, sem colocar o biombo" $(83,3 \%)$ e quando a "equipe de enfermagem troca sua roupa sem colocar o biombo" $(76,7 \%)^{14}$.

\section{Sobre as situações de desconforto}

Dos 30 idosos entrevistados, seis responderam que "não recordavam" e quinze "não tiveram", quando questionados sobre incidentes negativos relativos à invasão territorial e pessoal. Quatro idosos relataram que aconteceram coisas desagradáveis, porém que eram irrelevantes ou "quando se está internado, se deve aceitar tudo que acontece" durante sua estadia. Esses idosos não quiseram contar essas ocorrências, se limitaram somente ao comentário.

As mesmas expressões de conformismo e passividade foram verificadas em pesquisas com usuários do SUS no Rio Grande do Norte, nas quais revelaram naturalidade e aceitação diante do atendimento prestado. Esses usuários entendiam o atendimento recebido não como um direito, e sim, como um favor ou doação ${ }^{15}$.

Os demais cinco idosos (16,6\%) relataram incidentes negativos, sendo que três deles estão diretamente relacionados à invasão territorial e dois, à invasão pessoal. A seguir, a descrição de cada situação e do incidente revelado, bem como sua análise contextual.

\section{Situações que revelam invasão territorial}

Situação 1 - 0 idoso havia feito cirurgia há algumas horas, chega à unidade de internação e percebe ruídos. Ele conta "aqui as pessoas que trabalham falam de coisas pessoais num tom alto, isso não é nada bom, é até falta de respeito. Eu precisava dormir e descansar, tinha voltado da cirurgia, estava sob efeito da anestesia e tinha que ficar escutando tudo aquilo. Tive coragem de reclamar não, mas no dia seguinte eles acharam que eu tava nervoso, querendo minha família por perto."

A importância da comunicação no atendimento ao cliente hospitalizado é vital para se estabelecer um diálogo produtivo, positivo e ajustado às necessidades. Para que a comunicação seja efetiva é necessário estar sempre atento não só nas palavras, mas também aos gestos, expressões e atitudes, conforme já referido. Tanto a entonação como a ênfase da voz contribuem decisivamente para o êxito de uma conversação $0^{3}$. Sabe-se que 0 ato de baixar e levantar o tom de voz faz com que o discurso seja agradável às pessoas; contudo, na situação descrita, o tom da voz utilizada pela equipe atrapalhou o descanso e a recuperação do cliente.

Silva ${ }^{16}$ ressalta que o conhecimento ou não dos códigos não-verbais e o uso consciente dos comportamentos podem ser utilizados de maneira eficaz ou ineficaz na comunicação, considerando-os, conseqüentemente, como estímulos motivacionais positivos e/ou negativos em qualquer relação interpessoal, portanto também presentes na relação profissional-cliente.

Outra questão exposta com a situação descrita é o barulho que a equipe de saúde provoca ao desenvolver suas atividades. Estudo em um hospital estadual de São Paulo revelou que a maioria dos pacientes queixou-se de não conseguir dormir direito, devido às conversas em voz alta e ao barulho freqüente e intenso, que causavam alteração do estado do humor, deixando-os irritados e apreensivos. Neste estudo verificou-se que $68 \%$ dos pacientes pesquisados demonstraram desconfor to e irritabilidade quando a luz era acesa durante o período de sono ${ }^{17}$.

Por outro lado, tem-se que entender que o comportamento do idoso, quando hospitalizado, pode sofrer alterações como desorientação, não aceitação do tratamento e dos cuidados, entre outros. Muitas vezes a equipe considera o idoso como rebelde, agitado, confuso, quando na verdade, ele pode estar apresentando dificuldades de adaptação ao ambiente, que não é o dele, ou por estar junto de pessoas com as quais não convive ${ }^{18}$. Assim, é importante que a equipe esteja atenta para o que está velado ou oculto por trás das queixas, rebeldias e agitações dos idosos.

Situação 2 - 0 idoso falando muito baixo, pede para sair do quarto e conta "o senhor aqui do lado precisa que tirem as coisas da garganta. O pessoal vem aqui, liga o aparelho, que faz um barulho danado. Esquecem que eu tô aqui e fazem as coisas com ele. Depois eles querem que eu consiga comer, como que eu vou conseguir? Edormir então, isso nem se fala. Acabo saindo do quarto para agüentar a situação. Filha, não é falta de compreensão não, mas é que não é fácil, eu sou fraco para essas coisas".

Essa situação nos remete ao estudo realizado por Southwell, Wistow ${ }^{19}$ sobre o sono de clientes hospitalizados, onde foram levantados vários fatores que afetam seu sono, dentre eles: barulho provocado por outro cliente; ruídos causados pelo pessoal de enfermagem quando atendem o cliente do lado; conversas entre pessoal da equipe de enfermagem e luzes acesas na enfermaria. Os autores enfatizam que os enfermeiros precisam estar conscientes da importância do sono e proporcionar o menos possível sua interrupção.

Os profissionais de saúde devem estar atentos às necessidades básicas do indivíduo, seus pontos fortes e suas limitações. Ser sensível possibilita ampliar o leque perceptivo e não se restringir às formas convencionais de usar os sentidos. Agindo desse modo, não só facilita a promoção da saúde, como também impede que um agravo maior à saúde do indivíduo se instale. Utilizar-se de mecanismos de comunicação interpessoal é um dos caminhos que estreitam essa possibilidade e, conseqüentemente, pode proporcionar ao cliente uma assistência mais adequada, capaz de satisfazê-lo ${ }^{20}$.

A relação profissional na saúde é interpessoal (cliente e equipe), mas muitas das vezes trata-se de uma relação de interdependência desigual, pois o profissional, por deter 0 conhecimento do tratamento, tem um maior poder perante 0 cliente. Sentindo-se "dono" desse poder, negligencia a comunicação com o cliente e não percebe que atitudes como essa exposta, de tratar de um cliente na frente do outro, pode ser compreendida como desrespeito e gera angústia e dor tanto 
para quem está recebendo o cuidado como para quem está assistindo esse procedimento. Precisamos ficar atentos para essa realidade existente nos hospitais e pensar numa alternativa que possa favorecer um cuidado responsável e ético.

Situação 3-0 idoso demonstrando acanhamento lembra que "eles precisaram da cama, foi uma confusão, e eu precisei mudar de quarto, não sei por que, levei um susto com tanta gente falando, pensei que o pior estava por acontecer".

Carvalho ${ }^{8}$, em sua pesquisa, encontrou a entrada de médicos e enfermeiras sem permissão no território do cliente como uma das situações que causam maior aborrecimento aos clientes hospitalizados. Com base na teoria de territorialidade de Ardrey ${ }^{21}$, pode-se afirmar que o controle do espaço territorial pelo cliente contribui para a satisfação de sua necessidade de segurança, importante fator para sua recuperação.

0 cliente hospitalizado considera como seu espaço territorial do quarto ou enfermaria a cama e os objetos que 0 circundam. Para que se sinta respeitado, a equipe necessita bater na porta antes de entrar no quarto, informar sobre mudanças eventuais de leito e os motivos, pedir licença para alterar o lugar dos móveis que constituem sua unidade hospitalar. Alterar seu território sem maiores explicações é fonte de estresse para o idoso.

\section{Situações que revelam invasão pessoal}

Situação 4 - A idosa já internada há duas semanas comenta "aqui se ri de tudo, sabe?Até a hora do banho é uma diversão para eles, fazer o quê?".

Situação $5-0$ chuveiro apresentava problemas, a idosa precisava de ajuda e pede. A equipe chega e coloca na idosa uma toalha pequena, ela diz, "eu precisei sair enrolada nessa toalha, fiquei constrangida, quase morri de vergonha. Me levaram rapidinho para a cama e todo mundo que tava aqui viu a situação que fiquei".

As situações anteriores corroboram a afirmação feita por Waldow ${ }^{13}$ de que a dependência é observada como experiência constrangedora e que tolhe a liberdade do paciente, gerando insatisfações. Essa autora verificou que os pacientes muitas vezes se sentem humilhados ao necessitarem se despir ou serem higienizados na frente dos profissionais. Portanto, o idoso, nessas circunstâncias, se encontra exposto à perda de identidade e à falta da privacidade.

Sawada ${ }^{5}$ acrescenta que a invasão do território e do espaço pessoal fere a dignidade de qualquer indivíduo. Ressalta que a privacidade é uma necessidade e um direito do ser humano, sendo

\section{Referências}

1. Chaimowicz FA. Saúde dos idosos brasileiros às vésperas do século XXI: problemas, projeções e alternativas. Rev Saude Publica 1997; 31(2):184-200.

2. Veras RP. País jovem com cabelos brancos: a saúde do idoso no Brasil. Rio de Janeiro(RJ): Relume Dumará/UERJ; 1994.

3. Silva MJP. Comunicação tem remédio: a comunicação nas relações interpessoais em saúde. São Paulo(SP): Loyola; 2002. indispensável para a manutenção de sua individualidade. É oportuno citar os Códigos de Ética Médica e de Enfermagem ${ }^{22,23}$ que exigem "o respeito ao pudor, privacidade e a intimidade do cliente". Ao mesmo tempo, o profissional de saúde tem que reconhecer que o paciente possui o direito a atendimento humano, atencioso e respeitoso; tem o direito a um local digno e adequado para seu atendimento, o direito a manter sua privacidade para satisfazer suas necessidades fisiológicas, inclusive de alimentação e higiênicas, quer quando atendido no leito, no ambiente onde está internado ou aguardando atendimento ${ }^{24}$.

No tocante a esse aspecto, Pupulim, Sawada ${ }^{25}$ recomendam que sendo o membro da equipe de enfermagem o profissional em constante contato com o cliente durante a hospitalização, tem a responsabilidade de zelar pelo cuidado, resguardando os direitos do cliente. Alertam que tanto a enfermagem como outros profissionais devem procurar preservar a intimidade $\mathrm{e}$ a privacidade dos clientes usando biombos, cobrindo partes do corpo que não precisam ficar expostas durante um procedimento, como todos nós, talvez, já devêssemos não só saber, mas principalmente fazer.

\section{CONCLUSÕES E CONSIDERAÇÕES FINAIS}

Nesse estudo verificou-se que as situações de invasão territorial de desagrado dos idosos hospitalizados foram aquelas relacionadas ao barulho provocado pela equipe de enfermagem e, ainda, a desatenções da mesma equipe ao prestar cuidados a outros clientes, negligenciando a preservação da privacidade e das limitações do espaço do cliente. Já as de invasão pessoal foram aquelas ligadas à manipulação da unidade do cliente sem explicação e consentimento e ao desrespeito à intimidade com a banalização da exposição do corpo.

A população idosa representa uma clientela cada vez mais presente nos serviços de saúde, daí precisarmos aprender a cuidar das especificidades envolvidas e nos conscientizarmos da fonte benéfica que a comunicação interpessoal constitui. Urge que o cuidado integralizado seja uma realidade ao atendimento do idoso, portanto, respeitar a velhice e seu processo; utilizar uma abordagem individual centrada na pessoa, e não na doença; considerar o idoso como participante ativo no controle e no tratamento da saúde e lutar por condições cada vez mais humanas da assistência, as quais se ancorem na prática diária, nos mínimos cuidados, no respeito e na preservação da dignidade de nossos clientes.

4. Silva MJP. 0 aprendizado da linguagem não-verbal e o cuidar. In: Stefanelli MC, Carvalho EC,organizadores. A comunicação nos diferentes contextos da enfermagem. São Paulo(SP): Manole; 2005.

5. Sawada NO. 0 sentimento do paciente hospitalizado frente à invasão de seu espaço territorial e pessoal [tese de doutorado] Escola de Enfermagem de Ribeirão Preto/USP; 1995.

6. Hall ET. A dimensão oculta. Lisboa (P0): Relógio D’agua; 1986.

7. Allekian Cl. Instrusions of territory and personal space: an anxiety-inducing factor for hospitalized persons: an exploratory study. Nurs Res; 22(3): 236-41. 
8. Carvalho DV. Necessidade territorial do paciente hospitalizado [tese de doutorado] Escola de Enfermagem/USP; 1987.

9. Sommer R. Espaço pessoal. São Paulo (SP): EPU; 1973.

10. Barron A. The righ to personal space. Nurs Times 1990; 86(27): 28-33. 11. Horta WA. Processo de enfermagem. São Paulo (SP): EPUSP. 1979

12. Folstein MF, Folstein SE, Mc Hugh PR. Mini-mental state: a pratical method of grading the cognitive state of patientes for the clinician. J Psychiatr Res 1975; 12(3):189.

13. Waldow VR. Determinação do nível de dependência em enfermagem junto a idosos institucionalizados de Porto Alegre. Rev Gaucha Enferm 1987; 8(1): 46-73.

14. Prochet TC, Silva MJP. Proxêmica: as situações reconhecidas pelo idoso hospitalizado que caracterizam a invasão de seu espaço pessoal e territorial. Texto\& Contexto Enferm 2007. Em análise na editora.

15. Traverso-Yepez M, Morais NA. Reivindicando a subjetividade dos usuários da rede básica de saúde: para uma humanização do atendimento. Cad Saude Publica 2004; 20(1):80-88.

16. Silva MJP Construção e validação de um programa sobre comunicação não verbal para enfermeiros. [tese de doutorado] Escola de Enfermagem/ USP; 1993.

17. Salomé GM, Guerra CA. Sentimentos dos pacientes enfartados durante o período de internação em uma UTI. Enferm Brasil 2003; 2(3): 171-76.
18. Pedreira LC. Ser-idoso: vivência de internação em unidade de terapia intensiva. Salvador [dissertação de mestrado] Escola de Enfermagem: UFBa; 2000.

19. Southwell MT, Wistow G. Sleep in hospitals at night: are patients' needs being met? J Adv Nurs 1995; 21(6):1101-109.

20. Teixeira ER. A crítica e a sensibilidade no processo de cuidar na enfermagem. Esc Anna Nery Rev Enferm 2004; 8(3): 361-69.

21. Ardrey R. The territorial imperative. New York (USA): Atheneum Publ; 1966.

22. Resolução COFEN 311/2007. Aprova a reformulação do Código de Ética dos Profissionais de Enfermagem. In: Conselho Regional de Enfermagem. COREn Principais legislações para o exercício da enfermagem. São Paulo (SP): 2007. p. 21-33.

23. Resolução CFM 1246. Aprova o Código de Ética Médica. In: Gauderer EC. Os direitos do paciente: um manual de sobrevivência. 6 a ed. Rio de Janeiro (RJ): Record; 1998.

24. Lei 10.741, de 01 de outubro de 2003. Dispõe sobre o Estatuto do Idoso e dá outras providências. Diário Oficial da República Federativa do Brasil Brasília(DF) 2003 out 3.

25. Pupulim ISL, Sawada NO. 0 cuidado de enfermagem e a invasão da privacidade do doente: uma questão ético-moral. Rev Latino-am Enfermagem 2002; 10(3): 433-38. 